\title{
Tecnoestrés en el contexto educativo: Un problema emergente durante la pandemia COVID-19
}

\section{Technostress in the educational context: An emerging problem during the COVID-19 pandemic}

\author{
Estrada Araoz Edwin Gustavo ${ }^{1 \mathrm{a}}$; Gallegos Ramos Néstor Antonio ${ }^{2}$
}

Universidad Nacional Amazónica de Madre de Dios, Perú ${ }^{12}$

ORCID ID: https://orcid.org/0000-0003-4159-934X ${ }^{1}$

ORCID ID: https://orcid.org/0000-0003-1436-9207²

Recibido: 05 de julio de 2021

Aceptado: 12 de noviembre de 2021

Señor Editor:

En el mes de diciembre del año 2019 se reportó en la ciudad de Wuhan (China) casos de neumonía atípica ocasionadas por un nuevo coronavirus denominado SARS-CoV-2, causante de la enfermedad COVID-19 (Mojica \& Morales, 2020). Posteriormente, en el mes de marzo del año 2020 fue categorizada como pandemia debido al aumento exponencial de los casos en varios países (Buitrago et al., 2021), repercutiendo en el ámbito económico, social, financiero y cómo no, en la educación. En el Perú, como en otros países, la pandemia de COVID-19 ocasionó que el Gobierno declare el 15 de marzo del 2020 el estado de emergencia nacional y aislamiento social obligatorio como una medida excepcional para evitar que el virus se propague.

En ese sentido, muchas actividades fueron suspendidas, entre ellas, las actividades académicas en las instituciones educativas básicas y superiores. Posteriormente, y ante la necesidad 
de no interrumpir el servicio educativo, la modalidad de enseñanza pasó de ser presencial o semipresencial a ser estrictamente virtual a partir del mes de abril (Estrada \& Mamani, 2021).

En el caso de la educación básica, las clases comenzaron el 6 de abril con la estrategia "Aprendo en Casa", la cual buscó garantizar la continuidad del servicio educativo en el marco de la emergencia sanitaria. Para lograr dicho objetivo se puso a disposición algunos recursos como la televisión, la radio y una página web. En el caso de la educación superior, las clases comenzaron también a partir de abril, sin embargo, fue de manera progresiva, ya que muchas universidades e institutos las aulas virtuales no estaban operativas y en otros casos los actores educativos no estaban familiarizados con los recursos virtuales que tenían (Estrada et al., 2020a).

Por otro lado, la virtualización trajo consigo algunos problemas, tanto en los docentes como en los estudiantes, entre los que destaca el tecnoestrés. Este término fue introducido por Brod (1984) quien lo conceptualizó como la incapacidad individual para adaptarse de manera saludable al uso de las TIC, que se modula según la edad, las experiencias tecnológicas previas, el tiempo de conexión, la percepción, etc. y afecta el desempeño de las personas.

De acuerdo a diversas investigaciones, existen 3 tipos de tecnoestrés (Jiménez, 2010). En primer lugar está la tecnoansiedad, que posiblemente es el tipo más conocido. Es el estado en el que la persona siente elevados niveles de activación fisiológica, aumento de la tensión y malestar por la utilización actual o futura de las TIC. En segundo lugar se encuentra la tecnofatiga, la cual es caracterizada por el cansancio y agotamiento cognitivo como consecuencia de la utilización de las TIC y puede agudizarse por la presencia de sensaciones de desconfianza e ineficacia frente a su uso. Finalmente, se encuentra la tecnoadicción, que consiste en un fenómeno que se caracteriza por la constante necesidad de utilizar de manera obsesiva y compulsiva las TIC, en todo lugar y momento.

En el caso de la educación básica, los docentes, tuvieron la responsabilidad de elaborar sus sesiones de aprendizaje, adecuar los contenidos y recursos educativos propuestos por el Ministerio de Educación, ejecutar sus sesiones, responder a las dudas e inquietudes de los estudiantes en cuanto al desarrollo de las actividades, evaluar los trabajos, realizar el proceso de retroalimentación y atender a los padres de familia. Lo expuesto conllevó a que ellos sientan estresados, en muchos casos, debido a sus limitadas competencias digitales y la prolongada exposición a las TIC (especialmente desde laptops, tablets y smartphones). Asimismo, los estudiantes también tuvieron que estar conectados a las TIC, ya que debían participar de las sesiones de aprendizaje y ver los 
recursos elaborados por los docentes, desarrollar las actividades propuestas, interactuar con sus docentes y compañeros, enviar sus trabajos y recibir la retroalimentación sobre los mismos.

La realidad en la educación superior no difiere de lo expuesto, ya que los docentes también tuvieron que desarrollar sus sesiones de aprendizaje mediante videoconferencia, utilizando principalmente Google Meet, Zoom, WebEx y Microsoft Tems durante largos periodos, realidad a la que muchos no estaban acostumbrados ni preparados. Asimismo, tuvieron que calificar y retroalimentar los trabajos enviados al aula virtual. En el caso de los estudiantes de universitarios y de institutos, tuvieron que estar hiperconectados, es decir, participaron de las sesiones de aprendizaje mediante videoconferencias y realizaron sus demás responsabilidades académicas sobreexponiéndose a las TIC.

$\mathrm{Al}$ respecto, existen investigaciones que concluyeron que la virtualización de las clases en la educación básica y superior incrementó la prevalencia del tecnoestrés en los docentes (Penado et al., 2021; Estrada et al., 2021b; Boyer, 2020; Abo et al., 2021) y estudiantes (Christian, 2021; Montes de Oca et al., 2021; Ríos et al., 2020). Este problema deriva, tal como se mencionó, de la hiperconexión, los problemas en la conectividad y las limitadas competencias digitales (Montes de Oca et al., 2021). Lo preocupante es que el tecnoestrés puede traer secuelas en los diferentes aspectos de la vida de las personas que lo padecen.

Entre las consecuencias fisiológicas ocasionadas por el tecnoestrés están los problemas psicosomáticos, tales como la somnolencia, falta de concentración, los dolores oculares y de cabeza, dolencias musculares y problemas gastrointestinales (Salanova et al., 2007). En cuanto a las consecuencias psicosociales, el tecnoestrés puede ocasionar ansiedad, depresión, estrés y puede llegar a ocasionar a largo plazo burnout en el caso que la persona que lo padece no reciba tratamiento (Ragu et al., 2008).

Finalmente, podemos decir que las TIC se han convertido en los últimos años en una herramienta muy importante en todas las actividades humanas y por supuesto, en el proceso de enseñanza -aprendizaje. Sin embargo, en la pandemia se ha forzado la digitalización, incrementando especialmente los niveles de tecnoansiedad y tecnofatiga debido al uso constante y contraproducente en el desarrollo de las actividades académicas, y por otro lado, desnudando las limitaciones tecnológicas que muchos docentes tienen, creando en algunos casos tecnofobia.

Por ello, resulta imperativo que se tomen algunas medidas preventivas y correctivas que permitan disminuir la prevalencia de dicho padecimiento en ambos actores educativos. En primer 
lugar, es necesario fortalecer las competencias digitales de los docentes, tanto de educación básica y superior, y poner a disposición la asistencia técnica para que puedan solucionar los problemas que se les presente y mejoren su práctica pedagógica. En segundo lugar, resulta importante regular los horarios que tienen los docentes de educación básica para atender a sus estudiantes y padres de familia, ya que muchos de ellos suelen enviar sus trabajos sin respetar su jornada laboral establecida. En tercer lugar, es necesario incluir sesiones de clase asincrónicas en la educación superior y fijar tiempos prudenciales para el envío de las tareas con la finalidad de disminuir la hiperconexión. En cuarto lugar, las instituciones deben promover en los docentes y estudiantes estrategias como el autocontrol y las pausas activas durante la jornada académica para disminuir la tecnoansiedad y tecnofatiga. Finalmente, es menester fomentar la desconexión digital para que se realicen actividades físicas, de atención a la familia y socialización.

\section{Referencias}

Abo, A., Shayeb, S., Badah, A., Ismail, I., Ahmed, Y., Dawoud, L. \& Ayoub, H. (2021). Levels of technostress resulting from online learning among language teachers in Palestine during Covid-19 pandemic. American Journal of Educational Research, 9 (5), 243-254. https://doi.org/10.12691/education-9-5-1

Boyer, S. Technostress in higher education: An examination of faculty perceptions before and during the Covid-19 pandemic. Journal of Business and Accounting, 13 (1), 42-58. http://asbbs.org/files/2020/JBA_Vol_13.1_Fall_2020.pdf\#page=42

Brod, C. (1984). Technostress: The human cost of the computer revolution. USA: Addison-Wesley Publishing Company.

Buitrago, F., Ciurana, R., Fernández, M. \& Tizón, J. (2021). Pandemia de la COVID-19 y salud mental: reflexiones iniciales desde la atención primaria de salud española. Atención Primaria, 53 (1), 89-101. https://doi.org/10.1016/j.aprim.2020.06.006

Christian, M., Indriyarti, E. \& Wibowo, S. (2021) Investigating technostress as moderating information quality and e-learning effectiveness on students in Jakarta during the Covid-19 pandemic. Elementary Education Online, $20 \quad$ 46-52. http://dx.doi.org/10.17051/ilkonline.2021.04.07 
Estrada, C., Castillo, D., Vega, A. \& Boada, J. (2020b). Teacher technostress in the Chilean school system. International Journal of Environmental Research and Public Health, 17 (15), 1-17. https://doi.org/10.3390/ijerph17155280

Estrada, E., Gallegos, N., Mamani, H. \& Huaypar, K. (2020a). Actitud de los estudiantes universitarios frente a la educación virtual en tiempos de la pandemia de COVID-19. Revista Brasileira De Educação Do Campo, 5, e10237. https://doi.org/10.20873/uft.rbec.e10237

Estrada, E. \& Mamani, M. (2021). Competencia digital y variables sociodemográficas en docentes peruanos de educación básica regular. Revista San Gregorio, 1 (45), 1-16. http://dx.doi.org/10.36097/rsan.v0i45.1502

Jiménez, A. (2010). Tecnología como fuente de estrés: una revisión teórica al concepto de tecnoestrés. Temas de Comunicación, 21, 157-180. http://revistasenlinea.saber.ucab.edu.ve/temas/index.php/temas/article/view/433

Mojica, R. \& Morales, M. (2020). Pandemia COVID-19, la nueva emergencia sanitaria de preocupación internacional: una revisión. Medicina de Familia. SEMERGEN, 46 (1), 65-77. https://doi.org/10.1016/j.semerg.2020.05.010

Montes de Oca, J., Alcántara, S. \& Domínguez, A. (2021). Tecnoestrés en docentes y alumnos universitarios: medición en tiempos de COVID19. Revista de Desarrollo Sustentable, Negocios, $\quad$ Emprendimiento $\quad y \quad$ Educación, $\quad 16, \quad 98-109$. https://www.eumed.net/es/revistas/rilcoDS/16-febrero21/tecnoestres-docentes-alumnos

Penado, M., Rodicio, M., Ríos, M. \& Mosquera, M. (2020). Technostress in Spanish university students: Validation of a measurement scale. Frontiers of Psychology, 11, 1-9. https://dx.doi.org/10.3389\%2Ffpsyg.2020.582317

Ragu, T., Tarafdar, M., Ragu, B. \& Tu, Q. (2008). The consequences of technostress for end users in organizations: Conceptual development and empirical validation. Information Systems Research. 2008, 19 (4), 417-433. https://doi.org/10.1287/isre.1070.0165

Ríos, M., Penado, M., Rodicio, M., Mosquera, M. \& Rego, L. (2020). Tecnoestrés en estudiantes de la UDC durante el confinamiento COVID-19. CIVINEDU, 1, 654-655. https://iris.unimore.it/retrieve/handle/11380/1224199/307468/CIVINEDU2020.pdf\#page=6 $\underline{83}$

Salanova, M., Llorens, S., Cifre, E. \& Nogareda, C. (2007). Tecnoestrés: Concepto, medida e intervención psicosocial. España: Instituto Nacional de Seguridad e Higiene en el Trabajo. 